\title{
РАЗВИТИЕ И ПОДДЕРЖКА ДЕЯТЕЛЬНОСТИ СОЦИАЛЬНО ОРИЕНТИРОВАННЫХ НЕКОММЕРЧЕСКИХ ОРГАНИЗАЦИЙ (НА ПРИМЕРЕ ЯМАЛО-НЕНЕЦКОГО АВТОНОМНОГО ОКРУГА)
}

DEVELOPMENT AND SUPPORT
OF SOCIALLY ORIENTED NON-PROFIT
ORGANIZATIONS (ON THE EXAMPLE
OF THE YAMALO-NENETS AUTONOMOUS
OKRUG (DISTRICT), RUSSIA)
Summary. The article deals with the peculiarities of the development and
state support of socially oriented non-profit organizations on the territory
of the subject included in the Arctic zone of the Russian Federation Yamal-
Nenets Autonomous district.
Taking into account the nature of the activities of socially oriented non-
profit organizations, which at the current stage of the development of
Russian civil society are institutions created to achieve socially useful
goals, implement socially important initiatives, and therefore become an
integral part of our public life, affecting the sustainable socio-economic
development of both the region and the country as a whole.
At the same time, of particular importance is the need to build a system
of support and cooperation not only between state authorities, local
governments and business, but also between socially oriented commercial
organizations as equal subjects of interaction in order to combine joint
efforts to implement priority state programs for the country, including in
the Russian Arctic.
In this regard, the issues of studying and supporting the state's activities
for the development and support of socially oriented non-profit
organizations are relevant and subject to detailed research.
In the course of the presentation of the material, information is also
provided on the measures of regional support for socially oriented non-
profit organizations operating in the territory of the Yamalo-Nenets
Autonomous district.
Keywords: socially oriented non-profit organizations, social
entrepreneurship, state support for activities aimed at solving socially
significant issues.

\author{
Новосёлова Ирина Игоревна \\ Аспирант, Российская академия народного \\ хозяйства и государственной службы при Президенте \\ Российской Федерачии \\ novoselovaii72@mail.com
}

Аннотация. Настоящая статья посвящена особенностям развития и государственной поддержки деятельности социально ориентированных некоммерческих организаций применительно к территории субъекта, входящего в Арктическую зону Российской Федерации - Ямало-Ненецкого автономного округа (далее также - $\mathrm{CO} \mathrm{HКO).}$

Учитывая природу деятельности СО НКО, которые на сегодняшнем этапе развития российского гражданского общества являются институтами, с0зданными для достижения социально полезных целей, реализации общественно важных инициатив, в связи с чем становятся неотъемлемой частью нашей общественной жизни, влияющей на устойчивое социально-экономическое развитие, как региона, так и страны в целом.

При этом особую значимость приобретает необходимость выстраивания системы поддержки и сотрудничества не только между органами государственной власти, органами местного самоуправления и бизнесом, но и между СО НКО как равноправными субъектами взаимодействия в целях объединения совместных усилий для реализации приоритетных для страны государственных программ, в том числе в российской Арктике.

В этой связи вопросы изучения и поддержки деятельности государства по развитию и поддержке СО НКО является актуальными и подлежащими детальному исследованию.

В процессе изложения материала также представлены сведения о мерах региональной поддержки СО НКО, осуществляющих деятельность на территории Ямало-Ненецкого автономного округа.

Ключевые слова: социально ориентированные некоммерческие организации, социальное предпринимательство, государственная поддержка деятельности по решению социально значимых вопросов. 
$\Gamma$ лобальная климатическая повестка нашла свое отражение и в вопросах формирования государственной политики России.

Для поддержания конкурентоспособности российской экономики и придания ей «зеленого» импульса, нужна «пересборка» ее структуры для определения новых эффективных связей и новых пропорций между различными сферами производства товаров и услуг, которая позволит более эффективно обеспечить устойчивое социальное и экономическое развитие всех регионов, даже тех из них, где условия хозяйствования отличаются особой сложностью и агрессивностью.

Важно отметить, что эффект изменения климата усиливается на территориях Арктической зоны Российской Федерации (далее - АЗРФ, Арктика), где наличие населения, развитие природно-ресурсной и транспортной инфраструктуры и другая деятельность человека оказывают дополнительное давление на арктические экосистемы.

Содействие устойчивому развитию регионов в Арктике имеет решающее значение, поскольку хрупкость окружающей среды, особенности «северной» экономики и условия жизни населения в полярных широтах делают ошибки более дорогостоящими и, вероятнее всего, окажут длительное воздействие, чем в более устойчивой среде Центральной России.

Также растущее этническое, религиозное и культурное разнообразие населения АЗРФ бросает вызов социальной сплоченности местных сообществ и требует новых социальных стратегий гармонизации межэтнических и межконфессиональных отношений в регионе.

Проблемы преодоления глобальных климатических вызовов, и, как следствие, обеспечения устойчивого социально-экономического развития российской экономической системы и, соответственно, гражданского общества фундаментально взаимосвязаны с социальной политикой государства.

СО НKO, или, как их еще называют, общественные организации, заняли определенное положение в социальной политике страны и играют неотъемлемую роль.

Российским «правовым полем» определено, что в форме СО НКО могут быть организованы общины коренных малочисленных народов Российской Федерации, общественные и религиозные организации (объединения), казачьи общества и фонды, некоммерческие партнерства и частные учреждения, осуществляющие деятельность по социальной поддержке и защите граждан, по оказанию услуг в сфере образования и здравоох- ранения, по оказанию помощи пострадавшим в результате стихийных бедствий, экологических, техногенных или иных катастроф, социальных, национальных, религиозных конфликтов, беженцам и вынужденным переселенцам, по охране окружающей среды и защите животных и др.

С точки зрения новой социальной политики, ориентированной на устойчивое территориальное развитие, на заботу о качестве человеческого капитала населения, на гармонизацию межличностных (межэтнических и межконфессиональных) отношений, СО НКО являются серьезным дополнением в решении конкретных проблем социального благополучия в сферах здравоохранения, образования, духовного воспитания, спорта, культуры, природы, которые предопределяют масштаб соответствующих проблем эффективности экономических стратегий, реализуемых на разных уровнях управления.

Как правило, экспертные оценки условий, с которыми связано благополучие жизни человека на определённой территории, связаны с мониторингом таких направлений, как экономическое, экологическое и социальное измерение устойчивого развития.

Подробнее о содержании такового мониторинга с учетом контекста настоящей статьи: применительно к особенностям Арктики.

1. Экономическое измерение устойчивого развития включает в себя:

- устойчивую экономическую деятельность и повышение благосостояния арктических бизнес-сообществ;

- устойчивое и рациональное использование природных, в том числе биологических ресурсов;

- развитие транспортной инфраструктуры (включая авиационный, морской и наземный транспорт);

- развитие информационных технологий и современных телекоммуникаций.

2. Экологическое измерение имеет следующие приоритеты:

- мониторинг и оценка состояния окружающей среды и климата в Арктике;

- предотвращение и ликвидация загрязнения окружающей среды в Арктике;

- охрана морской среды Арктики;

- предупреждение и ликвидация чрезвычайных экологических ситуаций в Арктике, в том числе связанных с изменением климата.

3. Социальное измерение включает в себя:

- здоровье людей, живущих и работающих в Арктике

- образование и культурное наследие; 
- процветание и укрепление потенциала детей и молодежи;

- повышение благосостояния, борьба с бедностью и гендерное равенство среди арктических народов.

Очевидно, что в достижении положительных результатов по последним двум направлениям ощутимый вклад в силу специфики своей деятельности могут внести региональные СО НКО.

Формирование новой «зеленой» модели устойчивого экономического роста ставит перед регионами соответствующие задачи в области социально-экономического развития, в том числе увеличение доли малого и среднего бизнеса, привлечение дополнительных инвестиций в региональную экономику, рост удовлетворенности граждан социальной сферой региона.

Для решения последней из перечисленных задач требуется увеличение количества социальных поставщиков, улучшение качества их работы и повышение эффективности самой системы взаимодействия с ними.

Логичным способом решения является развитие в субъекте Российской Федерации института СО НКО, а впоследствии с ростом объема социальных услуг на соответствующих региональных рынках - социального предпринимательства.

Учитывая вопросы, которыми могут заниматься СО НКО и тот факт, что в силу своих законодательных особенностей могут одновременно финансироваться за счет разных источников: бюджетного финансирования, частного (адресного спонсорского/филантропического) финансирования, либо на принципах фандрайзинга (фандрайзинговые платформы в «Интернете»), то для субъекта Российской Федерации, в особенности, для «северного» региона, привлечение СО НКО с позиций экономической и бюджетной эффективности выгодно, в связи с чем целесообразно и оправдано.

Кроме того, перед субъектами Российской Федерации и их губернаторами, девятью национальными проектами поставлены амбициозные цели в период до 2024 года для развития социальной сферы «на местах» по таким направлениям, как образование, здравоохранение, культура, демография, экология, жилье и городская среда, малое и среднее предпринимательство и поддержка индивидуальной предпринимательской инициативы, производительность труда и поддержка занятости, международная кооперация и экспорт, а также эффективное достижение основной цели, которая ежегодно «красной нитью» отмечается в послании Прези- дента Российской Федерации - социального развития и благополучия граждан.

Сегодня ни для кого не секрет, что в общественном сознании укоренилось недовольство качеством социальных услуг: образование, здравоохранение, либо отсутствием доступности их получения в регионах.

Комплексное решение задач повышения социального, и, как следствие, инвестиционного, экономического рейтинга регионов («северных» регионов) и, соответственно, их губернаторов требует использование всех доступных механизмов.

Таким образом, если речь идет о формировании «зеленой» экономики - гаранта устойчивого прогресса, то она полиструктурна и включает в себя помимо экологической еще и социальную подструктуру, и, забота о целостности которой, также должна быть в фокусе всех уровней управления.

Тенденция на вовлечение СО НКО для решения вопросов, связанных с доступностью качественных социальных услуг и, как следствие, содействие реализации стратегических региональных целей по устойчивому социально-экономическому развитию, уверенно прослеживается в Ямало-Ненецком автономном округе (далее - ЯНАО, автономный округ, регион, Ямал).

При лобовом сравнении некоторых показателей деятельности СО НКО в субъектах, также входящих в АЗРФ, по итогам 2019 года становится очевидным, что ЯНАО занимает уверенные позиции по поддержке и развитию на своей территории института социально значимых общественных организаций. Подробнее в таблице 1

Применительно к эпидемиологически сложному прошлому году статистика деятельности региональных СО НКО следующая.

По данным Управления Министерства юстиции Российской Федерации по автономному округу по состоянию на 01 июля 2020 года на Ямале зарегистрировано 889 CO HKO (по даннылм Росстата, по итогам 2019 года на территории ЯНАО насчитьвалось 9 308 ед. организаций разных форм собственности), в том числе 358 общественных объединений, 66 религиозных организаций, из которых 31 входит в состав Салехардской епархии Русской православной церкви, 465 иных некоммерческих организаций.

Наибольшее число некоммерческих организаций зарегистрировано в городах Салехарде (184 организации, 20,6\%), Новом Уренгое (181 организация, 20,3\%) и Ноябрьске (136 организаций, 15,2\%). 
Таблица 1. Сравнение некоторых показателей деятельности СО НКО в субъектах, входящих в АЗРФ, по итогам 2019 года

\begin{tabular}{|c|c|c|c|c|c|c|}
\hline № ח/ח & $\begin{array}{l}\text { Наименование } \\
\text { субъекта, входяще- } \\
\text { го в АЗРФ }\end{array}$ & $\begin{array}{l}\text { Общее количе- } \\
\text { ство } \\
\text { СО НКО, ед. }\end{array}$ & $\begin{array}{l}\text { Из них количество } \\
\text { СО НКО, имеющих } \\
\text { помещение в со6- } \\
\text { ственности, ед. }\end{array}$ & $\begin{array}{l}\text { Поступило } \\
\text { денежных } \\
\text { средств и иное } \\
\text { имущество - } \\
\text { всего, млн. руб. }\end{array}$ & $\begin{array}{l}\text { Средняя числен- } \\
\text { ность работников } \\
\text { в организации - } \\
\text { СО НКО, чел. }\end{array}$ & $\begin{array}{l}\text { Средняя числен- } \\
\text { ность доброволь- } \\
\text { цев в организации } \\
\text { - СО НКО, чел. }\end{array}$ \\
\hline 1 & 2 & 3 & 4 & 5 & 6 & 7 \\
\hline 1 & Республика Коми & 1066 & 44 & 3965,3 & 3050 & 19839 \\
\hline 2 & $\begin{array}{l}\text { Ненецкий } \\
\text { автономный округ }\end{array}$ & 152 & 1 & 391,5 & 226 (min) & 2137 (min) \\
\hline 3 & \begin{tabular}{|l|} 
Архангельская \\
область (без АО)
\end{tabular} & 1322 & 44 & 3428,2 & 4087 & 17011 \\
\hline 4 & Мурманская область & 881 & 33 & 2410,1 & 1950 & 16953 \\
\hline 5 & ЯНАО & 761 & 27 & 5979,4 & 2093 & 11737 \\
\hline 6 & Красноярский край & 1924 (max) & 110 (max) & 8830,0 (max) & 7435 (max) & 27565 (max) \\
\hline 7 & $\begin{array}{l}\text { Республика Саха } \\
\text { (Якутия) }\end{array}$ & 884 & 43 & 4143,7 & 4084 & 3893 \\
\hline 8 & Чукотский авт.округ & 136 (min) & $2(\min )$ & 337,0 (min) & 344 & 2926 \\
\hline
\end{tabular}

Примечание: без учета данных по Республике Карелия (является частью АЗРФ в составе Лоухского, Кемского и Беломорского муниципальных районов) в связи с отсутствием их в свободном доступе.

Поддержка деятельности СО НКО на Ямале осуществляется на постоянной и системной основе.

Государственная поддержка СО НКО включает в себя финансовую поддержку (инфраструктурная поддержка, стимулирование проектной деятельности на конкурсной основе), информационная и методическая поддержки, поддержка в области подготовки дополнительного профессионального образования работников и добровольцев (на базе Центра инноваций социальной сферы ЯНАО, далее - ЦИСС ЯНАО), обеспечение доступа СО НКО к бюджетным средствам через осуществление обязательного объема закупок для государственных и муниципальных нужд (в соответствии с частью 1 статьи 30 Федерального закона от 05 апреля 2013 года № 44-Ф3 «О контрактной системе в сфере закупок товаров, работ, услуг для обеспечения государственных и муниципальных нужд»).

Также в качестве направления для государственной поддержки со стороны региона следует отметить возможность «накапливания экспертизы и нетворкинга» для СО НКО через серию специализированных общественных мероприятий (к примеру, «Школа социального предпринимательства» при поддержке ЦИСС ЯНАО).

По данным сайта департамента экономики ЯНАО финансовую поддержку СО НКО в ЯНАО оказывают 14 исполнительных органа государственной власти. За 9 месяцев 2020 года поддержка была оказана на сумму 1 574,6 млн. рублей.
За 9 месяцев 2020 года в безвозмездное пользование и в аренду на льготных условиях предоставлено 337,28 м² недвижимого имущества, 6 единиц транспорта и 26 единиц прочего имущества.

Общая сумма финансовой поддержки СО НКО, включая поддержку, оказанную органами местного самоуправления за 9 месяцев 2020 года, составила 1 698,8 млн. рублей.

Общая площадь недвижимого имущества, предоставленного СО НКО в безвозмездное пользование и в аренду на льготных условиях, включая имущество, предоставленное органами местного самоуправления

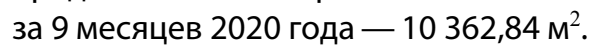

Информационное, консультационное и методическое сопровождение деятельности СО НКО и социальных предпринимателей осуществляется всеми исполнительными органами государственной власти ЯНАО и муниципальными образованиями.

Сведения о региональных получателях поддержки из числа СО НКО общедоступны и размещены на официальном сайте Правительства ЯНАО — «Реестр социально ориентированных некоммерческих организаций — получателей поддержки» (ссылка: http://reestrnko.yanao.ru/).

Общественный контроль за деятельностью СО НКО и качеством оказываемых ими услуг обеспечивается субъектами региональной системы общественного кон- 


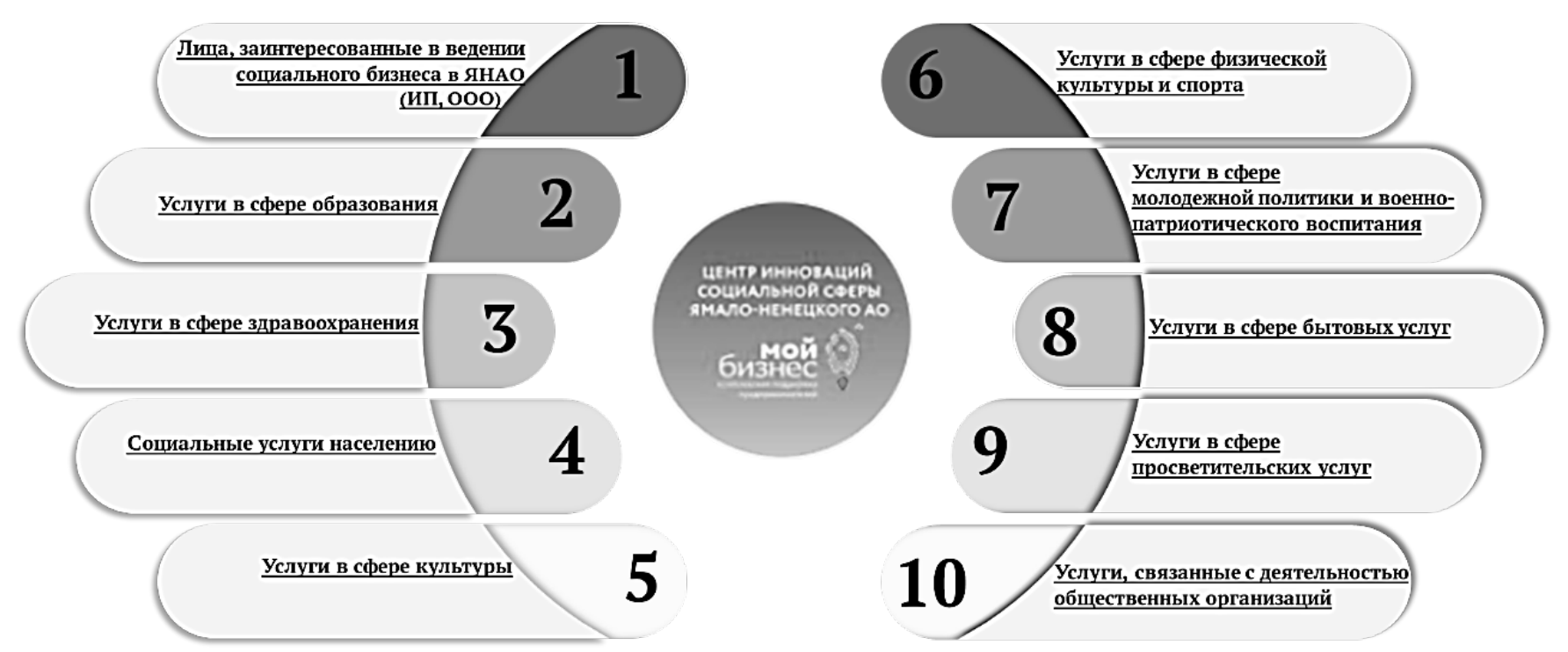

Рис. 1. Сведения об организациях, предоставляющих (планирующих предоставлять) услуги социального характера в ЯНАО

троля в автономном округе, среди которых Общественная палата, общественный совет при Законодательном Собрании, общественные советы при исполнительных органах государственной власти и муниципальные общественные палаты.

Действующий состав Общественной палаты утвержден в количестве 30 человек. При исполнительных органах государственной власти региона действует 33 общественных совета. В каждом из 6 городских округов и 7 муниципальных районов автономного округа образованы муниципальные общественные палаты.

Согласно информации, доступной на сайте ЦИСС ЯНАО, традиционно в зоне учета для привлечения к участию в различных мероприятиях (семинары, марафоны, конференции) по поддержке социально значимой общественной деятельности находятся организации, предоставляющие (планирующие предоставлять) услуги социального характера в сфере здравоохранения, образования, культуры и др. общественно полезные услуги. Подробнее на рисунке 1.

Данный перечень не является закрытым. Заинтересованными исполнительными органами власти ЯНАО также ведется постоянная работа по изучению лучших российских практик в части расширения деятельности региональных СО НКО для решения социально значимых проблем, в том числе в субъектах Российской Федерации со схожими особенностями хозяйствования, с целью применения соответствующего опыта на Ямале. К примеру, опыт оказания услуг иппотерапии для детей с задержкой психо-речевого развития и детей с аутизмом и обучению верховой езде - конный центр «Аврора», г. Сыктывкар, Республика Коми), услуги преподавания театроведения школьным педагогам - AНO «Пролог», г. Москва) и услуги профориентации различных групп и категорий молодёжи в агробизнесе - «Школа фермеров», Пермский край.

Важно отметить, что по итогам рейтинга субъектов Российской Федерации по уровню и качеству развития некоммерческого сектора, подготовленного в октябре 2020 года Общественной палатой России в партнерстве с рейтинговым агентством «РАЭКС-Аналитика», по такому показателю рейтинга, как «Поддержка СО НКО региональной властью» ЯНАО вошел в ТОП-20 лидеров по направлению из 85 субъектов Российской Федерации (в сумме 3,39 балла и 17 место).

При решении вопросов о развитии деятельности СО НКО в России и ее регионов - это использование обширной международной практики в части опыта работы с некоммерческими (неправительственными) организациями.

Один из примеров такой практики - это инициатива «The SunstainAbility Institute» (г. Лондон) в партнерстве с «UN Global Compact» (г. Нью-Йорк), Организацией Объединенных Наций в рамках их программы по охране окружающей среды (UNEP) (г. Париж) по подготовке в 2003 году отчета о неправительственных (некоммерческих) организациях в 21 веке (далее - НКО).

Согласно данному отчету в будущем, основанном на устойчивом общественном развитии, социально зна- 
чимые НКО станут важным фактором как в определении роли государства, так и в деятельности самих предприятий (бизнеса), по следующим направлениям:

- им отводится значимая роль в демократических и демократизирующихся обществах;

- необходимо учитывать, что проблемы, которые они решают, могут продолжать увеличиваться;

- НКО могут активно участвовать в разработке и внедрении инновационных решений;

- в процессе своей деятельности НКО могут столкнуться с конкуренцией со стороны коммерческих компаний и социальных предпринимателей, стирающих традиционные границы ведения экономической деятельности.

В связи с чем, как национальные, так и международные HKO, должны уделять больше внимания всей области брендинга и конкурентного позиционирования;

- параллельно с этим появится тенденция к актуализации, которая поставит НКО перед новыми требованиями отчетности для усиления контроля за источниками финансирования деятельности;

- с учетом ограниченности традиционных источников финансирования НКО (через государственный заказ и систему грантов) потребуется пересмотр и дальнейшее развитие бизнес-моделей HKO.

Для целей обеспечения устойчивого развития применительно к российской действительности целесообразно руководствоваться указанными направлениями в качестве стратегических ориентиров в вопросах совершенствования деятельности «отечественных» CO HKO.

В целом, сотрудничество государства и органов местного самоуправления с организациями «третьего сектора» - СО НКО в социальной сфере не только способно служить важным фактором повышения эффективности использования средств, в особенности выделяемых на социальные нужды, но и имеет вполне практическую мотивацию, связанную с поиском более эффективного использования доступных государству ресурсов для проведения социально-экономической политики, нацеленной на стабильное удовлетворение потребностей граждан в соответствующих услугах. При этом также важно учитывать, что их роль не ограничивается участием в решении только внутренних вопросов страны, СО HKO, в том числе являются частью международного сотрудничества.

Резюмируя представленную информацию, важно отметить, что что содействие устойчивому развитию - это теперь задача органов власти. Оказывая услуги населению сегодня, органы государственной власти должны заботиться о будущем. Углубление понимания необходимости более устойчивого развития происходит на фоне стремительного изменения климата, растущей нехватки ресурсов и растущего социального неравенства - все это представляет значительную угрозу для прогресса [7, C. 193].

В автономном округе, как территории с особо уязвимой и хрупкой арктической природой, региональным Правительством совместно с исполнительными органами государственной власти устойчивый подход к его развитию с заботой о будущих поколениях обеспечивается уже сегодня.

Это обеспечивается с помощью сбалансированной стратегии социально-экономического развития, адекватного нормативного регулирования, финансирования пилотных инициатив по созданию основ экосистемы умных городов, способных сформировать новые производственные отрасли (предоставить новые услуги), по разработке и внедрению социальных инноваций, в том числе через расширение деятельности региональных СО НКО, по содействию природоподобному промышленному освоению, что, в конечном итоге, будет способствовать финансовой стабильности, устойчивости окружающей среды, равноправию и благосостоянию населения региона в будущем.

\section{ЛИТЕРАТУРА}

1. О грантах Президента Российской Федерации, предоставляемых на развитие гражданского общества «Интернет»: Указ Президента Российской Федерации от 30 января 2019 года № 30.

2. 0 внесении изменений в отдельные законодательные акты Российской Федерации по вопросу поддержки социально ориентированных некоммерческих организаций «Интернет»: Федеральный закон от 5 апреля 2010 г. № 40-Ф3 [в ред. Федерального закона от 27 мая 2014 г. № 136-Ф3].

3. 0 контрактной системе в сфере закупок товаров, работ, услуг для обеспечения государственных и муниципальных нужд «Интернет»: Федеральный закон от 05 апреля 2013 года № 44-Ф3.

4. 06 утверждении перечня показателей, используемых для расчета рейтинга субъектов Российской Федерации по итогам реализации механизмов поддержки социально ориентированных некоммерческих организаций и социального предпринимательства, обеспечения доступа негосударственных организаций к предоставлению услуг в социальной сфере и внедрения конкурентных способов оказания государственных (муниципальных) услуг в социальной сфере «Интернет»: распоряжение Правительства Российской Федерации от 19 июня 2017 года № 1284-р. 
5. 0 внесении изменения в статью 1.1 Закона Ямало-Ненецкого автономного округа «0 налоговой ставке для налогоплательщиков, применяющих упрощенную систему налогообложения и выбравших в качестве налогообложения доходы» «Интернет»: Закон ЯНАО от 25.09.2020 № 95-3А0.

6. $0 б$ утверждении комплексного плана мероприятий Ямало-Ненецкого автономного округа по обеспечению поэтапного доступа социально ориентированных некоммерческих организаций, осуществляющих деятельность в социальной сфере, к бюджетным средствам, выделяемым на предоставление социальных услуг населению, использованию различных форм поддержки деятельности социально ориентированных некоммерческих организаций на 2019-2020 годы «Интернет»: распоряжение Правительства ЯНАО от 27 июня 2019 № 406-РП.

7. Абучакра, Раби Эффективное правительство для нового века: Реформирование государственного управления в современном мире [Текст] / Раби Абучакра, Мишель Хури. — М.: Издательство «Олимп-Бизнес», 2016 с.— 256 с.

8. Алешин, М.В. Социальная политика в современной России: социологический анализ тенденций инклюзии [Текст]: моногр. / М.В. Алешин, И.В. Бабаян, Д.В. Зайцев и др .; изд. Зайцев Д.В., Ярская В.Н.- М.: СГТУ, 2010.- 132 с.

9. Гаджиев, К.С. Гражданское общество. Мировой опыт и проблемы России [Текст] / К.С. Гаджиев.— М.: Знак, 2008.— 176 с.

10. Зверева, Н.И. Атлас практик развития социального предпринимательства субъектами Российской Федерации [Текст] / Н.И. Зверева, Бесшапошникова Е.Н., Сидорова 0.А., Панчетовская Л.В., Шлыкова 0.В.— М.: Фонд региональных социальных программ «Наше будущее», 2019. - 65 с.

11. Красин, Ю.А. Развитие гражданского общества. Русский пазл [Текст] / Красин Ю.А. // Полис.— 2012.— № 2. Стр. 36-39.

12. Московская, А.А. Социальное предпринимательство в России и в мире: практика и исследования [Текст] / отв. ред. А.А. Московская; Нац. исслед. ун-т «Высшая школа экономики».—- М.: Изд. дом Высшей школы экономики, 2011. - 284 с.

13. [Электронный ресурс]: Доклад о деятельности и развитии социально ориентированных некоммерческих организаций в $2019-2020$ гг.- Режим доступа: https://goo.su/4aMS (дата обращения. 10.02.2021).

14. [Электронный ресурс]: Социальное предпринимательство и социально ориентированные организации ЯнА0.— Режим доступа: https://mb89.ru/ciss (дата обращения. 10.02.2021).

15. [Электронный ресурс]: 0 деятельности некоммерческих организаций. Информационный портал Министерства юстиции РФ.— Режим доступа: http:// unro.minjust.ru (дата обращения. 10.02.2021).

16. [Электронный ресурс]: 00Н Женева.— - Режим доступа: https://goo.su/4aN5 (дата обращения. 10.02.2021).

17. ЭЭлектронный ресурс]: Продвижение ценностей Глобального договора. Региональная программа. — Режим доступа: https://go0.su/4An5 (дата обращения. 10.02.2021).

(c) Новосёлова Ирина Игоревна ( novoselovaii72@mail.com ).

Журнал «Современная наука: актуальные проблемы теории и практики»

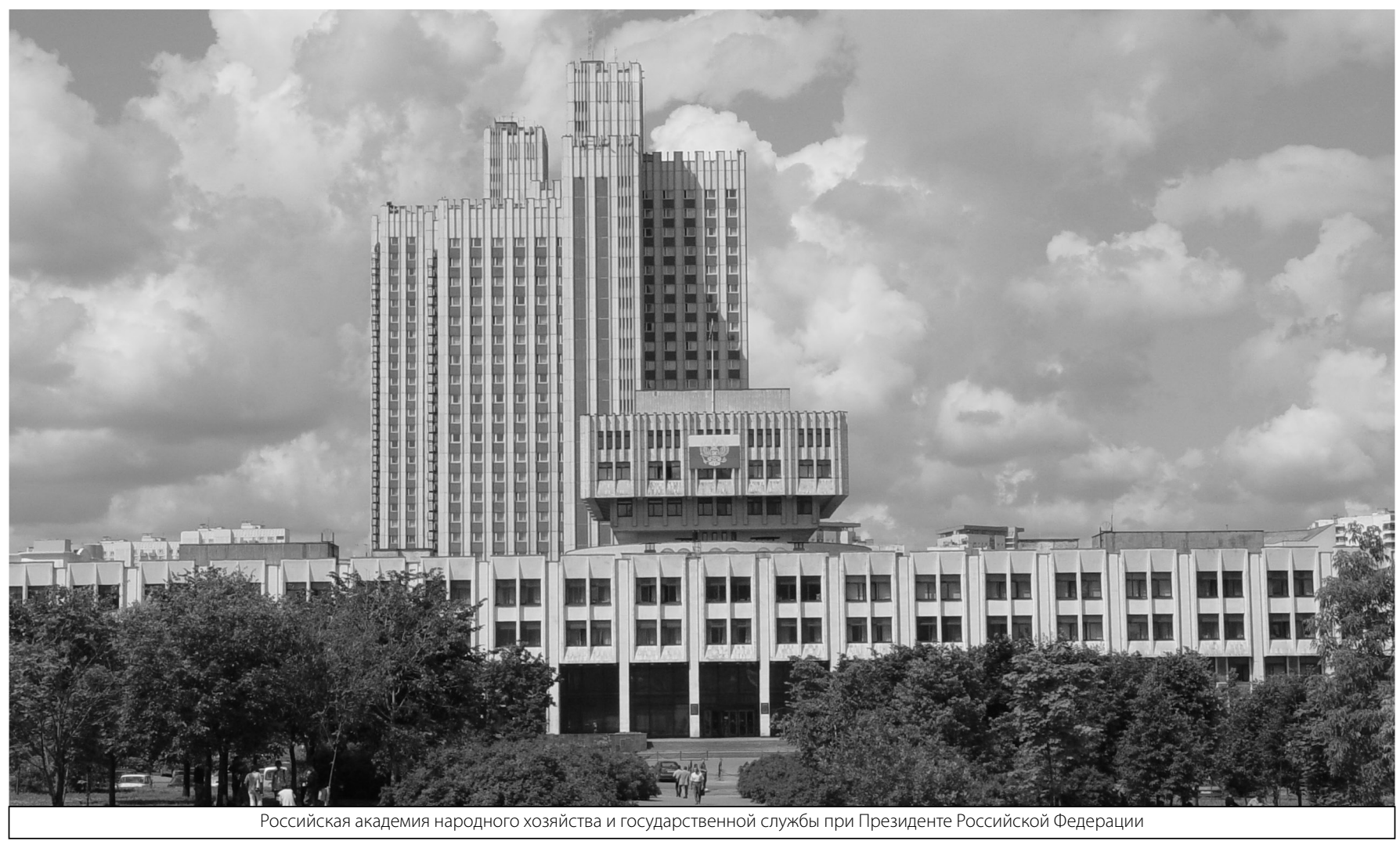

